\title{
Pengaruh Kebutuhan akan Prestasi dan Kecerdasan Emosional terhadap Intensi Wirausaha Murid SMK di Jawa Timur
}

\author{
JAYA DWI KARUNIA \& FAJRIANTHI* \\ Fakultas Psikologi Universitas Airlangga
}

\begin{abstract}
ABSTRAK
Penelitian ini bertujuan untuk mengetahui apakah terdapat pengaruh antara kebutuhan akan prestasi dan kecerdasan emosional terhadap intensi wirausaha pada siswa SMK di Jawa Timur. Subyek dalam penelitian ini merupakan siswa sekolah menengah kejuruan (SMK) yang sedang menempuh pendidikan di Jawa Timur yang berjumlah 70 orang. Alat ukur yang digunakan dalam penelitian ini adalah kuesioner intensi wirausaha (Entrepreneurial Intention Questionnaire) untuk mengukur kemampuan intensi wirausaha, skala kebutuhan akan prestasi untuk mengukur variabel kebutuhan akan prestasi dan trait emotional intelligence questionnaire short form (TEIQue-SF) untuk mengukur variabel kecerdasan emosional. Pendekatan kuantitatif digunakan dalam penelitian ini menggunakan aplikasi SPSS Statistics 25. Hasil analisis data menunjukkan bahwa ada pengaruh positif pada kebutuhan akan prestasi dan kecerdasan emosional terhadap intensi wirausaha siswa sekolah menengah kejuruan (SMK) di Jawa Timur dengan besar pengaruh $\mathrm{R}^{2}$ sebesar 0,222 . Namun secara parsial tidak terdapat pengaruh antara kebutuhan akan prestasi dengan intensi wirausaha.
\end{abstract}

Kata kunci: intensi wirausaha, kebutuhan akan prestasi, kecerdasan emosional

\begin{abstract}
This study aims to determine the effect of need for achievement and emotional intelligence on entrepreneurial intention for vocational high school students in East Java. The subjects in this study were students of vocational high school in East Java, totaling of 70 people. The measuring instruments used are Linan's entrepreneurial intention questionnaire to measure the entrepreneurial intentions, need for achievement questionnaire scale to measure the need for achievement and trait emotional intelligence questionnaire (TEIQue-SF) to measure the emotional intelligence. The quantitative approach used in this study uses the SPSS Statistics 25 application. The results of data analysis show that there is a positive influence on the need for achievement and emotional intelligence on the entrepreneurial intentions of vocational high school students in East Java with a large $\mathrm{R}^{2}$ effect of 0.222. However, partially there is no influence between the need for achievement and entrepreneurial intentions.
\end{abstract}

Keywords: entrepreneurial intention, emotional intelligence, need for achievement

Buletin Penelitian Psikologi dan Kesehatan Mental (BRPKM), 2021, Vol. 1(2), 1369-1378

*Alamat korespondensi: Fakultas Psikologi Universitas Airlangga, Kampus B Universitas Airlangga Jalan Airlangga 4-6 Surabaya 60286. Surel: fajrianthi@psikologi.unair.ac.id 
sehingga penggunaan, distribusi, reproduksi dalam media apapun atas artikel ini tidak dibatasi, selama sumber aslinya disitir dengan baik.

\section{P E N D A H U L U A N}

Kegiatan berwirausaha atau kewirausahaan memiliki peranan penting dalam pertumbuhan ekonomi suatu negara, karena untuk mengatasi permasalahan suatu negara seperti kurangnya lapangan pekerjaan, kemiskinan, dan daya beli rendah dibutuhkan adanya tingkat kewirausahaan yang tinggi pada suatu negara berkembang (Frinces, 2010). Tingginya tingkat wirausaha pada suatu negara berkembang juga mampu meningkatkan pertumbuhan ekonomi, memperkaya inovasi-inovasi baru pada sector kewirausahaan, dan penciptaan kekayaan yang dapat membantu suatu negara dalam persaingan global (Chaudhary, 2016). Indonesia sendiri baru memiliki 3,1\% sektor usaha dari jumlah total penduduknya, sedangkan untuk menjadi suatu negara maju dalam sektor usaha diperlukan setidaknya $14 \%$ sektor usaha pada suatu negara, sehingga Indonesia masih memiliki perjalanan panjang dan dibutuhkan strategi untuk mendorong munculnya pelaku kewirausaahan (Ristianto, 2019).

Lulusan sekolah menengah kejuruan dalam data milik Badan Pusat Statistik pada tahun 2020 di Jawa Timur mendominasi jumlah pengangguran dibandingkan dengan lulusan jenjang pendidikan yang lain sebesar 8,04\% (Badan Pusat Statistik, 2020). Padahal lulusan sekolah menengah kejuruan tidak hanya diharapkan sebagai lulusan yang siap kerja untuk dunia profesional, namun juga diharapkan agar dapat membuka lapangan pekerjaannya sendiri karena telah diberikan kemampuan kejuruan dan pendidikan kewirausahaan semasa sekolahnya untuk membantu menurunkan angka pengangguran dan membantu ekonomi negara (Oktaviana \& Umami, 2018). Pemerintah mendorong para lulusan sekolah menengah kejuruan agar dapat melakukan kegiatan wirausaha untuk mempersiapkan mereka pada dunia kerja dengan menerapkan beberapa hal, yaitu diaturnya dalam standar kelulusan sekolah menengah kejuruan agar semua lulusan sekolah menengah kejuruan memiliki kemampuan kewirausahaan (Kementrian Pendidikan dan Kebudayaan, 2018). Selanjutnya adalah disusunya kompetensi pembelajaran umum kelompok B yang isinya adalah kemampuan prakarya dan kewirausahaan (Kementrian Pendidikan dan Kebudayaan RI, 2013). Terbatasnya lapangan pekerjaan ditambah adanya pandemi covid-19 membuat semakin tingginya jumlah pengangguran (Suryowati, 2020).

Pemerintah sedang mendorong dan mengupayakan program peningkatan kewirausahaan untuk murid sekolah menengah kejuruan untuk mengatasi tingginya pengangguran dan kurangnya sektor wirausaha, beberapa cara yang dilakukan adalah dengan beberapa program yang tujuannya untuk menciptakan bibit-bibit wirausahawan seperti teaching factory yang berguna mendorong murid agar dapat membuat dan memproduksi karya mereka sendiri (Kementrian Pendidikan dan Kebudayaan RI, 2019).

Intensi wirausaha menjadi hal penting dalam pembentukan seorang wirausahawan sehingga perlu dikaji lebih lanjut mengenai faktor-faktor yang membuat seseorang menjadi seorang wirausahawan dan perkembangan seorang wirausahawan, karena tanpa adanya intensi wirausaha maka seseorang tidak akan menjadi seorang wirausahawan (Koe dkk., 2012). Intensi wirausaha bukanlah kemampuan dari lahir, melainkan sesuatu yang dapat dibentuk dalam perkembangan seseorang (Koe dkk., 2012). Maka dari itu intensi wirausaha diharapkan dapat ditumbuhkan sejak dini dalam diri seseorang, karena tingkat pendidikan menurut penelitian yang dilakukan oleh Sesen pada tahun 2013 tidak ditemukannya hubungan antara lingkungan perkuliahan dengan intensi wirausaha seseorang (Sesen, 2013). Murid 
sekolah menengah kejuruan pada umumnya sudah memasuki masa tentatif dimana mereka mulai eksploratif dalam penentuan karirnya mendatang (Ginsberg dkk., 1951).

Intensi wirausaha seseorang umumnya dipengaruhi oleh tiga faktor yaitu individu, demografis, dan kontekstual (Indarti \& Rostiani, 2008). Pada faktor individu salah satunya terdapat kebutuhan akan prestasi, dimana menurut penelitian sebelumnya terdapat pengaruh yang signifikan antara kebutuhan akan prestasi terhadap intnesi wirausaha, dikarenakan individu dengan kebutuhan akan prestasi tinggi akan memiliki rasa tanggung jawab, dan mampu menghadapi tantangan (Ermawati dkk., 2017). Namun pada penelitian lain, ditemukan bahwa kebutuhan akan prestasi tidak berhubungan secara signifikan tehadap intensi wirausaha (Barba-Sánchez \& Atienza-Sahuquillo, 2017). Adanya perbedaan hasil membuat peneliti menggunakan kebutuhan akan prestasi sebagai salah satu variabel dalam penelitian ini.

Kecerdasan emosional juga dinilai penting dalam pembentukan intensi wirausaha, karena dengan kecerdaan emosional tinggi seseorang mampu mengelola, mengekspresikan, dan meregulasi emosinya dengan baik (Chamola \& Jain, 2017). Peneliti menggunakan kecerdasan emosional sebagai variabel dalam penelitian ini dikarenakan masih kurangnya penelitian yang melihat pengaruh kebutuhan akan prestasi dan kecerdasan emosional secara langsung terhadap intensi wirausaha.

\section{Intensi Wirausaha}

Intensi wirausaha didefinisikan sebagai keinginan dan niatan yang dimiliki seseorang untuk menjalankan suatu usaha dan memiliki kesiapan dalam membangun sebuah usaha (Linan, 2008). Intensi wirausaha juga dianggap sebagai faktor yang dapat memprediksi apakah seseorang memiliki niatan atau keinginan untuk memulai sebuah usaha (Krueger dkk., 2010). Intensi wirausaha juga dianggap penting karena berdasarkan penelitian-penelitian sebelumnya ditemukan bahwa seseorang yang memiliki intensi wirausaha akan cenderung untuk memiliki komitmen dalam melakukan sebuah kegiatan usaha pada masa mendatang dihidupnya (Hattab, 2014).

Intensi wirausaha sendiri dikembangkan dari teori intensi milik Ajzen (1991), yaitu theory of planned behavior, dikarenakan theory of planned behavior dinilai efektif untuk mengukur intensi wirausaha pada seseorang (Van Gelderen dkk., 2008).

Teori intensi theory of planned behavior milik Ajzen (1991) memiliki tiga dimensi yaitu attitude toward the behavior, subjective norm, dan perceived behavoral control. Dari ketiga dimensi ini dikembangan oleh Linan (2008) menjadi sebuah alat ukur untuk mengukur intensi wirausaha pada seseorang menjadi empat dimensi yaitu personal attraction, subjective norm, general self-efficacy, dan intention (Linan, 2008).

Berdasarkan penjelasan intensi wirausaha yang dipaparkan diatas, peneliti menggunakan teori intensi wirausaha milik Linan (2008) yang didasari teori intensi milik Ajzen (1991) sebagai dasar untuk memahami dan mengukur intensi wirausaha pada seseorang.

\section{Kebutuhan akan Prestasi}

Kebutuhan akan prestasi didefinisikan oleh McClelland (1965) sebagai usaha yang dilakukan seseorang dalam upaya untuk meraih kesuksesan untuk menjadi seseorang yang lebih baik, sukses, dan menjadi pribadi yang berkompeten. McClelland (1965) juga menyatakan bahwa seseorang dengan kebutuhan akan prestasi akan memiliki keinginan yang kuat untuk menyelesaikan tugas yang menantang, bertanggung jawab dengan tindakannya, dan menyukai/mengharapkan umpan balik pada hasil 
pekerjaan yang dilakukannya. Kebutuhan akan prestasi juga didefinisikan sebagai dorongan dalam diri seseorang untuk dapat meraih kesuksesan dan mencapai titik yang lebih tinggi diatas orang lain (Karabulut, 2016).

Kebutuhan akan prestasi terdiri dari dua faktor yaitu internal dan eksternal, pada faktor internal terdapat jenis kelamin, usia, kepribadian, dan self-efficacy. Pada fator eksternal terhadap tingkat kesulitan, resiko tugas, dan organisasi (McClelland, 1965).

\section{Kecerdasan Emosional}

Kecerdasan emosional didefinisikan sebagai kemampuan untuk memonitor emosi diri sendiri dan orang lain untuk kemudian diggunakan sebagai hasil pemikiran dan aksi yang akan dilakukan (Petrides \& Furnham, 2001). Kecerdasan emosional juga didefinisikan sebagai kemampuan dalam mengetahui dan mengekspresikan emosi seseorang, menyatukan emosi dalam pikiran, memahami emosi diri sendiri dan orang lain, dan meregulasi emosi (Chamola \& Jain, 2017).

Kecerdasan emosional sendiri terbagi menjadi tiga konsep yaitu ability, trait, dan mixed dimana konsep trait dipandang sebagai konsep yang tepat digunakan untuk mengukur kecerdasan emosi seseorang dikarenakan konsep trait milik Petrides \& Furnham (2001) memandang kecerdasan emosional sebagai kecenderungan dasar perilaku yang menetap dan memiliki konsistensi respon dalam situasi yang berbeda-beda. Selain itu konsep trait dipandang sebagai sifat yang berhubungan dengan emosi dan persepsi yang telah berulang kali terbukti mempengaruhi berbagai variabel psikologis dan perilaku. Operasionalisasi trait kecerdasan emosi juga dinali lebih mudah dalam mengukur kecerdasan emosional sesoerang dikarenakan konstruk trait mencakup persepsi diri dan disposisi yang sesuai dengan sifat subjektif seseorang (Petrides \& Furnham, 2001).

Berdasarkan penjelasan mengenai intensi wirausaha, kebutuhan akan prestasi, dan kecerdasan emosional, penelitian ini Menyusun hipotesis sebagai berikut:

- $\mathrm{H}_{1}$ : Terdapat pengaruh signifikan antara kebutuhan akan prestasi dan kecerdasan emosional terhadap intensi wirausaha pada murid sekolah menengah kejuruan di Jawa Timur.

- $\mathrm{H}_{2}$ : Terdapat pengaruh siginifikan kebutuhan akan prestasi terhadap intensi wirausaha pada murid sekolah menengah kejuruan di Jawa Timur

- $\mathrm{H}_{3}$ : Terdapat pengaruh signifikan kecerdsasan emosional terhadap intensi wirausaha pada murid sekolah menengah kejuruan di Jawa Timur

\section{Desain Penelitian}

\section{E T O D E}

Pada penelitian ini menggunakan penelitian kuantitatif, yaitu penelitian yang menggunakan data dalam bentuk angka untuk kemudian diolah dengan metode statistik. Penelitian ini menggunakan data primer dengan menggunakan alat ukur berupa kuisioner yang diarahkan langsung kepada subjek sebagai individu yang paling memahami dirinya sendiri (Azwar, 2011). Penelitian ini merupakan cross-sectional dimana peneliti mengumpulkan data dari satu waktu tertentu pada populasi subjek yang telah ditentukan. Tipe penelitian ini adalah penelitian eksplanatori yaitu jenis penelitian yang dilakukan untuk mendapatkan kejelasan dari masalah dan penjelasan kausal antar variabel melalui uji hipotesis (Neuman, 2006). 


\section{Partisipan}

Partisipan pada penelitian ini merupakan murid sekolah menengah kejuruan di Jawa Timur dari kelas satu hingga kelas tiga. Penelitian ini menggunakan teknik non-probability sampling dengan metode accidental sampling. Teknik non-probability sampling adalah teknik yang memberikan kesempatan tidak sama besar bagi anggota populasi untuk dipilih, sedangkan metode accidental sampling adalah metode pengambilan data berdasarkan kebetulan, sehingga sampel penelitian dapat terpilih karena berada pada tempat, waktu, dan situasi yang tepat (Azwar, 2011). Partisipan dalam penelitian ini diberikan inform consent yang terdapat pada halaman pertama kuesioner penelitian.

Jumlah minimal subjek dalam penelitian ini menggunakan software $g^{*}$ power dengan hasil minimal adalah 68 subjek, pada penelitian ini digunakan 73 subjek yang terdiri dari murid laki-laki berjumlah 35 orang dan murid perempuan berjumlah 38 orang.

\section{Pengukuran}

Peneliti menggunakan entrepreneurial intention questionnaire (EIQ) milik Linan (2008) yang telah diterjemahkan dalam Bahasa Indonesia dan telah diuji reliabilitas dan validitasnya oleh Amatilah (2017) untuk mengukur intensi wirausaha. Skala ini terdiri dari 20 item yang disusun menggunakan skala likert dengan tujuh rentang respon 1 sampai 7 (" 1 " = sangat tidak sesuai dengan diri saya hingga "7" = sangat sesuai dengan diri saya). Dalam mengukur kebutuhan akan prestasi menggunakan alat ukur milik Karabulut (2016) yang telah diadaptasi dan diuji reliabilitas dan validitasnya oleh Afifah (2019). Skala ini terdiri dari 10 item yang disusun menggunakan skala likert dengan tujuh rentang respon 1 sampai 7 ("1" = sangat tidak sesuai dengan diri saya hingga "7" = sangat sesuai dengan diri saya). Skala trait emotional intelligence questionnaire short form (TEIQue-SF) milik Petrides \& Furnham (2001) yang telah diadaptasi dan diuji validitas dan reliabilitasnya oleh Amatilah (2017), digunakan untuk mengukur kecerdasan emosional. Skala ini terdiri dari 30 item yang sisusun menggunakan skala likert dengan tujuh rentang respon 1 sampai 7 ("1" = sangat tidak sesuai dengan diri saya hingga "7" = sangat sesuai dengan diri saya).

Validitas alat ukur intensi wirausaha dan kecerdasan emosional pada penelitian ini telah diuji oleh Amatilah (2017) dengan teknik validitas content validity. Selanjutnya, untuk validitas alat ukur kebutuhan akan prestasi pada penelitian ini telah diuji oleh Afifah (2019) dengan teknik validitas content validity.

Reliabilitas juga sudah diukur menggunakan Alpha Omega untuk intensi wirausaha dan Cronbach's Alpha untuk kebutuhan akan prestasi dan kecerdasan emosional. Peneliti menggunakan skala intensi wirausaha dengan Alpha Omega sebesar $(\alpha=0,710)$. Alat ukur kebutuhan akan prestasi dengan Cronbach's Alpha sebesar $(\alpha=0,795)$. Terakhir yaitu alat ukur kecerdasan emosional dengan Cronbach's Alpha $(\alpha=0,733)$.

\section{Analisis Data}

Uji asumsi klasik yang dilakukan menunjukan sebaran data normal dan linear. Uji multikolinearitas yang telah dilakukan menunjukan tidak adanya gejala multikolinearitas yaitu tidak adanya hubungan korelasi antar variabel bebas. Uji heteroskedastisitas berdasarkan scatter plot menunjukan bahwa tidak ada permasalahan dan gejala heteroskedastisitas karena titik-titik menyebar diatas dan dibawah angka nol pada sumbu Y. Dari hasil uji asumsi yang dilakukan dapat dikatakan bahwa data dalam penelitian ini memenuhi semua syarat uji asumsi. Selanjutnya, dilakukan analisis menggunakan analisis regresi berganda. Dalam mengolah data yang ada digunakan software IBM SPSS Statistic 25 for Windows. 


\section{HAS IL PENELITIAN}

Hasil analisis deskriptif menunjukan bahwa partisipan yang memiliki intensi wirausaha sangat tinggi sebanyak 6 partisipan (8,6\%), dalam kategori tinggi sebanyak 18 partisipan (25,7\%), dalam kategori sedang sebanyak 25 partisipan (35,7\%), dalam kategori rendah sebanyak 15 partisipan $(21,4 \%)$, dan dalam kategori sangat rendah sebanyak 6 partisipan $(8,6 \%)$. Untuk kategorisasi kebutuhan akan prestasi sangat tinggi sebanyak 3 partisipan (4,3\%), dalam kategori tinggi sebanyak 21 partisipan (30\%), dalam kategori sedang sebanyak 25 partisipan (35,7\%), dalam kategori rendah sebanyak 13 partisipan (18,6\%), dan dalam kategori sangat rendah sebanyak 8 partisipan (11,4\%). Untuk kategorisasi kecerdasan emosional sangat tinggi sebanyak 7 partisipan (10\%), dalam kategori tinggi sebanyak 11 partisipan (15,7\%), dalam kategori sedang sebanyak 29 partisipan (41,4\%), dalam kategori rendah sebanyak 21 partisipan (30\%), dan dalam kategori sangat rendah sebanyak 2 partisipan $(2,9 \%)$.

Hasil analisis regresi linear sacara parsial antara kebutuhan akan prestasi terhadap intensi wirausaha menunjukan bahwa kebutuhan akan prestasi dapat menjelaskan intensi wirausaha pada murid sekolah menengah kejuruan di Jawa Timur sebesar 10,8\% $\left(\mathrm{F}(1,68)=8,250 ; p<0,089 ; R^{2}=0,108\right)$. Kebutuhan akan prestasi secara signifikan tidak berpengaruh terhadap intensi wirausaha murid sekolah menengah kejuruan dikarenakan nilai $p>0,05$ sehingga $\mathrm{H}_{1}$ ditolak $(B=0,289 ; p<0,089)$.

Hasil analisis regresi linear sacara parsial antara kecerdasan emosional terhadap intensi wirausaha menunjukan bahwa kecerdasan emosional dapat menjelaskan intensi wirausaha pada murid sekolah menengah kejuruan di Jawa Timur sebesar 18,7\% $\left(F(1,68)=15,653 ; p<0,003 ; R^{2}=0,187\right)$. Kecerdasan emosional secara signifikan berpengaruh terhadap intensi wirausaha murid sekolah menengah kejuruan dikarenakan nilai $p<0,05$ sehingga $\mathrm{H}_{2}$ diterima $(B=0,243 ; p<0,003)$.

Selanjutnya hasil analisis linear berganda menunjukan bahwa kebutuhan akan prestasi dan kecerdasan emosional dapat menjelaskan $22 \%$ dari variabel intensi wirausaha pada murid sekolah menengah kejuruan di Jawa Timur $\left(F(2,67)=9,543 ; p<0,000 ; R^{2}=0,222\right)$. Kebutuhan akan prestasi secara signifikan tidak berpengaruh terhadap intensi wirausaha pada murid sekolah menengah kejuruan di Jawa Timur $(B=0,289 ; p<0,089)$, kemudian kecerdasan emosional memiliki pengaruh yang signifikan terhadap intensi wirausaha murid sekolah menengah kejuruan di Jawa Timur $(B=0,243 ; p<0,003)$.

\section{I S K U S I}

Tujuan dari penelitian ini adalah untuk melihat pengaruh kebutuhan akan prestasi dan kecerdasan emosional terhadap intensi wirausaha pada murid sekolah menengah kejuruan di Jawa Timur. Berdasarkan analisis yang telah dilakukan, ditemukan hasil yang menunjukan bahwa kebutuhan akan prestasi tidak berpengaruh secara signifikan terhadap intensi wirausaha pada murid sekolah menengah kejuruan di Jawa Timur. Sumbangan pengaruh yang diberikan kebutuhan akan prestasi terhadap intensi wirausaha adalah 10,8\% dan selebihnya dipengaruhi oleh faktor lain yang tidak diteliti dalam penelitian ini.

Hasil dari penelitian ini memperkuat penelitian yang telah dilakukan oleh Sarwoko (2011) yang menunjukan bahwa kebutuhan akan prestasi tidak memiliki pengaruh signifikan terhadap intensi wirausaha, dan sesuai dengan pendapat Scapinello (1989) yang mengatakan bahwa individu dengan kebutuhan akan prestasi yang tinggi kurang dapat mengatasi kegagalan padahal untuk menjadi wirausahawan diperlukan kemampuan untuk menghadapi kegagalan (Sarwoko, 2011). Indarti \& Rostiani (2008) juga menyatakan tidak adanya pengaruh antara kebutuhan akan prestasi terhadap 
intensi wirausaha dikarenakan individu dengan kebutuhan akan prestasi yang tinggi di beberapa negara seperti Indonesia, Norwegia, dan Jepang merasa pencapaiannya tinggi apabila dapat bekerja pada perusahaan besar dibandingkan dengan memiliki usaha yang sukses (Indarti \& Rostiani, 2008). Hal ini berkaitan dengan pentingnya pendidikan kewirausahaan agar murid dapat memiliki pandangan terkait kesuksesan menjadi lebih luas, tidak hanya bekerja pada perusahaan besar saja (Ndofirepi, 2020).

Selanjutnya, dari analisis regresi yang dilakukan ditemukan bahwa kecerdasan emosional memiliki pengaruh yang signifikan terhadap intensi wirausaha pada murid sekolah menengah kejuruan di Jawa Timur. Sumbangan pengaruh kecerdasan emosional terhadap intensi wirausaha adalah sebesar 18,7\% dan selebihnya dipengaruhi oleh faktor lain yang tidak diteliti pada penelitian ini.

Hasil dari penelitian ini memperkuat penelitian-penelitian sebelumnya yang menyatakan bahwa kecerdasan emosional memiliki pengaruh yang signifikan terhadap intensi wirausaha, seperti pada penelitian milik Miao dkk. (2018) yang menyatakan bahwa adanya pengaruh kecerdasan emosional terhadap intensi wirausaha. Lebih lanjut Miao dkk. (2018) menyatakan bahwa kecerdasan emosional mempengaruhi keadaan emosi seseorang dengan pemahaman tentang masa depan yang tinggi, hal ini berkaitan dengan menjalankan sebuah usaha memerlukan waktu yang tidak instan danjuga seringkali dihadapkan dengan banyak tantangan. Kecerdasan emosional juga mempengaruhi bagaimana seseorang dapat melakukan pekerjaan lebih efektif dengan berbagai macam cara.

Kecerdasan emosional trait sebagai dimensi dasar dari kepribadian mempengaruhi intensi wirausaha, pertama dikarenakan individu dengan kecerdasan emosional yang tinggi akan dapat mempengaruhi seseorang melalui evaluasi diri dari trait kecerdasan emosional karena seseorang dengan trait kecerdasan emosional yang tinggi akan dapat mengatasi tekanan karena memiliki toleransi tinggi terhadap stress yang dihadapi, individu dengan kecerdasan emosional yang tinggi akan memiliki tingkat afektivitas tinggi yang akan memunculkan disposisi proaktif dan kreatif yang dapat membuat individu dalam mood yang buruk dan keadaan yang menghimpit untuk menemukan cara-cara baru dalam menyelesaikan masalah (Zampetakis dkk., 2009). Hal ini membuat individu dengan tingkat kecerdasan emosional tinggi dapat meresap pengaruh positif maupun negatif untuk dengan tepat mengidentifikasi dan memecahkan masalah yang berkaitan dengan pembangunan ataupengembangan usaha (Zampetakis dkk., 2009).

Terakhir, berdasarkan dari hasil analisis berganda menunjukan bahwa variabel kebutuhan akan prestasi dan kecerdasan emosional secara bersama-sama memiliki pengaruh yang signifikan terhadap intensi wirausaha murid sekolah menengah kejuruan di Jawa Timur.

\section{S I M P U L A N}

Penelitian ini dilakukan untuk menguji apakah ada pengaruh yang signifikan antara kebutuhan akan prestasi dan kecerdasan emosi terhadap intensi wirausaha pada siswa sekolah menengah kejuruan di Jawa Timur. Hasil penelitian ini menunjukkan bahwa ada pengaruh dari kebutuhan akan prestasi dan kecerdasan emosional terhadap intensi wirausaha pada siswa sekolah menengah kejuruan di Jawa Timur sehingga $\mathrm{H}_{1}$ diterima. Selain itu kebutuhan akan prestasi tidak berpengaruh signifikan terhadap intensi wirausaha, dan kecerdasan emosional berpengaruh signifikan terhadap intensi wirausaha sehingga $\mathrm{H}_{2}$ ditolak dan $\mathrm{H}_{3}$ diterima.

Saran untuk penelitian selanjutnya adalah memperbesar subjek penelitian agar didapatkan gambaran yang lebih bai kantar variabel terhadap subjek, perlu adanya penelitian lebih lanjut terhadap variabel kebutuhan akan prestasi terhadap intensi wirausaha dikarenakan hasil yang masih beragam, dan perlu 
diteliti lebih lanjut tentang variabel mediator antara kebutuhan akan prestasi terhadap intensi wirausha mengingat adanya pengaruh lingkungan dalam pandangan kebutuhan akan prestasi.

Saran untuk murid sekolah menengah kejuruan dan pihak sekolah adalah melakukan bimbingan konseling kelompok dan achievement motivation training guna menunjang kebutuhan akan prestasi dan kecerdasan emosional murid. Perlu lebih memperhatikan pendidikan kewirausahaan terutama terhadap individu bukan hanya teknik, dan perlu memberikan pengetahuan lebih tentang kewirausahaan.

\section{U C A P A N T E R IMAKASIH}

Penulis berterima kasih kepada para partisipan yang sudah mengisi kuesioner penelitian ini dan membantu penulis dalam mengumpulkan data. Penulis juga ingin mengucapkan terima kasih kepada semua pihak yang sudah membantu penulis untuk menyelesaikan penelitian ini, yang sayangnya tidak bisa disebutkan satu per satu.

\section{DEKLARAS I POTENSI TERJADINYAKONFLIK KEPENTINGAN}

Jaya Dwi Karunia dan Fajrianthi tidak bekerja, menjadi konsultan, memiliki saham, atau menerima dana dari perusahaan atau organisasi manapun yang mungkin akan mengambil untung dari diterbitkannya naskah ini.

\section{PUSTAKA ACUAN}

Afifah, A. (2019). Hubungan antara Need for Achievement dan Proactive Personality terhadap Intensi Berwirausaha Mahasiswa. [Skripsi, Universitas Airlangga]. http://repository.unair.ac.id/82615/.

Ajzen, I. (1991). The Theory of Planned Behavior. Organizational behavior and human decision processes, 50(2), 179-211. https://doi.org/10.1016/0749-5978(91)90020-T.

Amatilah, M. (2017). Pengaruh Kecerdasan Emosional terhadapan Intensi Kewirausahaan dengan Entrepreneurial Self-Efficacy sebagai Variabel Mediator. [Skripsi, Universitas Airlangga]. http://repository.unair.ac.id/59882/

Azwar, S. (2011). Metode Penelitian. Pustaka Belajar.

Barba-Sánchez, V., \& Atienza-Sahuquillo, C. (2017). Entrepreneurial Intention among Enginering Students: The Role of Entrepreneurship Education. European research on management and business economics, 24(1), 53-61. https://doi.org/10.1016/j.iedeen.2017.04.001

Badan Pusat Statistik. (2020). Keadaan Ketenagakerjaan Jawa Timur, Februari 2020 (No. 33).

Chamola, P., \& Jain, V. K. (2017). Towards Nurturing Entrepreneurial Intention from Emotional Intelligence. SIBM Pune Research Journal, 13, 26-34. https://dx.doi.org/10.2139/ssrn.3511369

Chaudhary, R. (2016). Demographic Factors, Personality, and Entrepreneurial Inclination. Education+ Training, 59(2), 171-181. https://doi.org/10.1108/ET-02-2016-0024

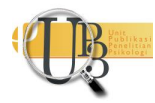


Ermawati, N., Soesilowati, E., \& Prasetyo, E. (2017). Pengaruh Need for Achievement dan Locus of Control terhadap intensi berwirausaha melalui sikap siswa kelas xii SMK negeri se kota Semarang. Journal of Economic Education, 6(1), 66-74. https://doi.org/10.15294/jeec.v6i1.14704

Frinces, H. (2010). Pentingnya Profesi Wirausaha di Indonesia. Jurnal ekonomi dan pendidikan, 7(1), 3557. http://dx.doi.org/10.21831/jep.v7i1.576

Ginsberg, E., Ginsburg, S. W., Axelrad, S., \& Herma, J. L. (1951). Occupational choice: An approach to a general theory. Columbia University Press.

Hattab, H. W. (2014). Impact of Entrepreneurial Education on Entrepreneurial Intention of University Students in Egypt. The Journal of Entrepreneurship, 23(1), 1-18. https://doi.org/10.1177\%2F0971355713513346

Indarti, N., \& Rostiani, R. (2008). Intensi Kewirausahaan Mahasiswa: Studi Perbandingan antara Indonesia, Jepang, dan Norwegia. Jurnal Ekonomi Dan Bisnis Indonesia, 23(4), 1-27.

Karabulut, A. T. (2016). Personality Traits on Entrepreneurial Intention. Procedia-Social and Behavioral Sciences, 229, 12-21. https://doi.org/10.1016/j.sbspro.2016.07.109

Kementrian Pendidikan dan Kebudayaan RI. (2013). Kurikulum 2013 Sekolah Menengah Kejuruan.

Kementrian Pendidikan dan Kebudayaan RI. (2018). Peraturan Menteri Pendidikan dan Kebudayaan Republik Indonesia Nomor 34 Tahun 2018 Tentang Standar Nasional Pendidikan Menengah Kejuruan.

Kementrian Pendidikan dan Kebudayaan. (2019). Mendikbud Dorong Siswa SMK Jadi Wirausaha di Era Industri 4.0. https://www.kemdikbud.go.id/main/blog/2019/03/mendikbud-dorong-siswasmk-jadi-wirausaha-di-era-industri-40

Koe, W.-L., Sa'ari, J. R., \& Ismail, K. (2012). Determinants of Entrepreneurial Intention Among Millennial Generation. Procedia-Social and Behavioral Sciences, 40, 197-208. https://doi.org/10.1016/j.sbspro.2012.03.181

Krueger, N., Reilly, M. D., \& Carsrud, A. (2010). Competing Models of Entrepreneurial Intention. Journal of Business Venturing, 15(5-6), 411-432. https://doi.org/10.1016/S0883-9026(98)00033-0

Linan, F. (2008). Skill and Value Perceptions: How Do They Affect Entrepreneurial Intentions? International Entrepreneurship and Management Journal, 4(3), 257-272.

McClelland, D. (1965). N Achievement and Entrepreneurship. Journal of Personality and Social Psychology, 1(4), 389-392. https://psycnet.apa.org/doi/10.1037/h0021956

Miao, C., Humphrey, R. H., Qian, S., \& Pollack, J. M.. (2018). Emotional intelligence and entrepreneurial intentions: An exploratory meta-analysis. Career Development International, 23(5), 497-512. https://doi.org/10.1108/CDI-01-2018-0019

Ndofirepi, T. M. (2020). Relationship between entrepreneurship education and entrepreneurial goal intentions: psychological traits as mediators. Journal of Innovation and Entrepreneurship. 9(1), 1-20. https://doi.org/10.1186/s13731-020-0115-x. 
Neuman, W. L. (2006). Social Research Methods. Boston: Pearson Education.

Oktaviana, V. D., \& Umami, N. (2018). Pengaruh Efikasi Diri dan Kreativitas terhadap Intensi Berwirausaha pada Siswa Kelas XI SMK Negeri 1 Pogalan Tahun Ajaran 2017/2018. Jurnal Pendidikan Ekonomi, 11(2), 80-88.

Petrides, K. V., \& Furnham, A. (2001). Trait Emotional Intelligence: Psychometric Investigation with Reference to Established Trait Taxonomies. European Journal of Personality, 5(6), 425-448. https://doi.org/10.1002/per.416

Ristianto, C. (2019). Wiranto: Syarat Negara Maju 14 Persen Warganya Wirausahawan. https://nasional.kompas.com/read/2019/04/08/16592321/wiranto-syarat-negara-maju-14persen-warganya-wirausahawan

Sarwoko, E. (2011). Kajian Empiris Entrepreneur Intention Mahasiswa. Jurnal Ekonomi Dan Bisnis Indonesia, 126-135.

Scapinello, K. F. (1989). Enhancing Differences in the Achievement Attributions of High- and LowMotivation Groups. The Journal of Social Psychology, 129(3), 357-363. https://doi.org/10.1080/00224545.1989.9712052

Sesen, H. (2013). Personality or Environment? A Comperhensive study on the entrepreneurial intention of university students. Education+ training, 55(7), 624-640. https://doi.org/10.1108/ET-052012-0059

Suryowati, E. (ed.). (2020). Lapangan Kerja Minim, Lulusan SMK Dominasi Angka Pengangguran. Ekonomi. https://www.jawapos.com/ekonomi/06/11/2020/lapangan-kerja-minim-lulusansmk-dominasi-angka-pengangguran/

Van Gelderen, M.., Brand, M., \& Praag, M. V. (2008). Explaining Entrepreneurial Intention by Means of the Theory of Planned Behavior. Career Development International, 13(6), 538-559. https://doi.org/10.1108/13620430810901688

Zamoetakis, L., Bouranta, N., \& Kafetsios, K. (2009). On the relationship between emotional intelligence and entrepreneurial attitudes and intentions. International Journal of Entrepreneurial Behaviour \& Research, 15(6), 595-618. https://doi.org/10.1108/13552550910995452 